\title{
Paradigm Shift in Research: Emergence of Mixed Methods Research Design
}

Dr. Nabaraj Neupane

\begin{abstract}
Between the lines of quantitative and qualitative inquiries, mixed methods research, which has taken a considerable space in academia, has emerged as a promising design as a mark of paradigm shift from pure method to the hybrid one. In this context, this article aims to explore the phenomenon of the mixed methods research design in terms of reasons for use, historical developments, types, and assessments. To achieve this goal, document analysis method has been used. Only the secondary sources like books, journals and archives have been used for documenting information and making meaning from them. The conclusion is that mixed methods research design has been a current practice for many reasons in academia. This implies that the new paradigm should profusely be used in the field of research at universities and research centers.
\end{abstract}

Keywords: concurrent, embedded, multiphase, sequential, transformative

\section{Introduction}

Along with the wave of postmodernism everywhere, mixed methods research design made its debut as a new paradigm for the researchers. The newcomer is a good blending of traditional research methods viz. quantitative and qualitative. Despite their strengths, both of them have been criticized for their weaknesses. Although the quantitative method has a long- established tradition, qualitative researchers regard quantitative research for being "overly simplistic, decontextualized, reductionist in terms of generalizations, and failing to capture the meaning that actors attach to their lives and circumstances" (Brannen, 2005, as cited in Dörnyei, 2007, p. 39). Likewise, quantitative researchers criticize qualitative research in terms of small sample size, lack of generalizability, biased researcher role, lack of methodological rigour, too complex or too narrow theories, time consuming, and labour-intensive (Dörnyei, 2007, p.41-42). Of these limitations, some (like the last two in this list) are confessed even by the qualitative researchers. In the similar vein, Denzin and Lincoln (2018) have made a mention of four-faced attacks on qualitative inquiry such as political, epistemological, ethical, and economic, representing methodological conservatives, neotraditionalist methodologists, traditional social science researchers, and advocates of global audit culture, respectively. Thus, between these two lines of worldviews, the third one made its debut as a new paradigm to overcome the weaknesses and to encapsulate the strengths of the two methods. As the name itself suggests, the mixed methods research design (MMRD) mixes up or combines or integrates both the traditional methods in such a way that quantitative part uses numbers and numerical data, and qualitative part uses textual and discoursed forms of data. These polarized methods have come together to form the intermediate form of inquiry. To put in Miles and Huberman's (1994) words:

Entertain mixed methods. We have sought to make a virtue of avoiding polarization, polemics, and life at the extremes. Quantitative and qualitative inquiry can support and inform each other. Narratives and variable-driven analyses need to interpenetrate and inform each other. Realists, 
idealists, and critical theorists can do better by incorporating other ideas than by remaining pure. Think of it as hybrid vigour. (as cited in Dörnyei, 2007, p.42)

This shows that MMRD has come out in the domain of research to incorporate the extremists' views of objective reality (quantitative) and subjective one (qualitative). This newcomer, which is a byproduct of the polemic paradigm war, amalgamates positivists' (quantitative) and interpretivists' or constructivists' (qualitative) positions. These two positions can be located at the two edges of a paradigm continuum that allows intermediate methods subsuming the newcomer. In this sense, MMRD is a mongrel and an intermediate approach to incorporate both the independent standpointson its left and right.

Before it received its labeling as mixed methods research design, it got different appellations like "multitrait-multimethod research, interrelating qualitative and quantitative data, methodological triangulation, multimethodological research, mixed model studies, and mixed methods research" (Creswell et al., 2003, as cited in Dörnyei, 2007, p.42).For Dorneyei (2007), MMRD has increasingly been used as a newcomer in research domain of the social sciences for the past 15 years. This confirms that MMRD has been in practice in a way or the other for a few years of history. It has been considered an influential way of integrating two polaristic standpoints. Although some researchers take these two as opposing views, the researchers or theorists assume the two (i.e. quantitative and qualitative) to be supportive to each other. It means that the two views support each other not in supplementary or complementary but in circular ways (Strauss \& Corbin, 1998, as cited in Dörnyei, 2007). It implies that they are not caricatural to each other but facilitative in a spiral manner in such a way that one helix supports the other in an evolving series of a research process.

Thus, Creswell and Plano Clark (2011) have defined this design as "a procedure for collecting, analysing, and 'mixing' both quantitative and qualitative methods in a single study or a series of studies to understand a research problem" (Creswell, 2012, p. 535). This fundamental premise has further been clarified by Creswell (2015b) in these words, "Mixed methods is an approach in which the investigator collects, analyses, and interprets both quantitative and qualitative data (closed- and open-ended information), integrates or combines the two approaches in various ways" (p. 59). Furthermore, this research design "uses a mix of quantitative and qualitative methodologies to examine that problem deductively and inductively so that findings will be explainable" (Hay, 2016, p. xii). In this way, this design has made its third space in the field of research.

The Multimethod design can sometimes be mistaken for the MMRD. To clarify, Creswell (2015a) and Hesse-Biber and Johnson (2015) have conceded that the former employs the collection and analysis of multiple forms of either quantitative or qualitative data whereas the later uses not only the collection and analysis of the both forms of data but also integrates of mixes up the two datasets along with interpretation. The distinctive traits of a typical MMRD are as follows:

i Collection and analysis of quantitative and qualitative data in response to research questions.

ii Use of rigorous qualitative and quantitative data using a specific type of mixed methods design, and interpretation of this integration.

iii Sometimes, framing of the design within a philosophy or theory. 
(Creswell, 2015a, p. 3)

The researchers interplay between the two methods in each step of the research process from collecting data to drawing inferences. This context makes the research process more advanced than the other two; the procedures are time-consuming and labour-intensive as the researcher should bear the double load of the approaches; and MMRD needs to link or embed two strands in such a way that the loopholes must remain invisible. Thus, the newcomer is an emerging yet demanding approach to overcome the shortcomings of either one.

Based on these contexts, this article aims to explore the reasons for using MMRD, to explore its historical developments, to delve into its taxonomy along with the salient features of each type, and to assess its uses in the research domain.

\section{Methodology}

To achieve the set goal, I have employed document analysis method as a part of qualitative approach. This is, thus, a secondary research that "includes any research based on secondary sources, especially other researchers' books and articles" and "is further divided into library research and literature reviews" (Brown \& Rodgers, 2014, p. 10). Thus, secondary research adds to the common body of existing knowledge. As a secondary research, this article analyses and interprets available documents within the domain/s selected (Bell, 1999, as cited in Al-Jardani, 2012, \& Krippendorff, 2013). Accordingly, I have selected the domain of mixed methods research design (MMRD), and analysed and interpreted the documents within the framework of parameters of the phenomenon such as reasons for use, historical developments, typologies, and assessments of its uses to draw inferences.

\section{Review, Result and Discussion}

This section reviews, analyses, and interprets the phenomenon of MMRD in terms of the four themes (as per the objectives) such as reasons of its use, historical developments, taxonomy along with the salient features of each type, and assessment of its uses in the research domain.

\section{Reasons for Use}

The mixed methods research design (MMRD) calls for understanding both qualitative and quantitative strands on the part of a researcher, who should mix up the two as an integrated whole. Thus, the main condition for using this design is the expertise in both the approaches. Although it is a rigorous process, the researchers need to follow its principles as this is a requirement for an innovative researcher to follow the advanced procedures. For Creswell (2012), these are the reasons for the need of its use:

i Mixed methods research is a good design to use if you seek to build on the strengths of both quantitative and qualitative data.

ii One type of research (qualitative or quantitate) is not enough to address the research problem or answer the research questions.

iii You want to provide an alternative perspective in a study.

iv On a practical level, you use mixed methods research for studies in graduate programs in which qualitative research has yet to be fully accepted and in which quantitative approaches are the 
norm.

v A mixed methods study is more acceptable than a 'pure' qualitative study because there is still a component of quantitative research in a study.

vi Graduate students use mixed methods research in order to learn and experience this form of research design so that they are well-informed about the latest research approaches. Mixed methods research has become popular as the newest development in research methods and in approaches to 'mixing' quantitative and qualitative research.

(Creswell, 2012, pp. 534-536)

These reasons confirm that MMRD is a safer and more reliable research journey than either quantitative or qualitative alone. To put in metaphorically, its researcher is to follow a double-lane road whereas either of the two is to follow a single-lane road. Naturally, the former way is comparatively safer if the researcher is expert in both the types of enquiry. To put it in a straight way, MMRD is more advanced because it catches the strengths of the both wings (i.e. quantitative and qualitative) to build on more strength (Anderson, 2016). For example, qualitative data facilitate in formulating survey questionnaires and quantitative data in formulating open-ended interviews or observations.

Thus, Miles and Huberman (1994) have asserted, "When one mixes quantitative and qualitative data, "we have a very powerful mix" (as cited in Dörnyei, 2007, p. 535). Further, the mix up of the products of the study with the process enhances "a complex" picture of a social phenomenon (Greene \& Caracelli, 1997, as cited in Creswell, 2012, p.535). Therefore, for the deeper study of an issue, MMRD is needed. To elaborate, the once collected data (quantitative), the researcher needs to revisit the phenomena (qualitative) in a naturalistic setting. For example, objective reality of a classroom culture maintained by a survey needs to re-examine through multiple lenses to diagnose subjective reality. Conversely, subjective reality may need to quantify objectively for the validity and reliability of the research process and product. So, following only one method paralyzes the product and needs to reincarnate by means of concurrent or sequential approaches in a circular way. This offers an alternative perspective to the usual one.

In universities, the quantitative design may have been a convention and therefore purely qualitative enquiry may not be accepted. In such contexts, the graduate students need to follow the mixed one. Further, researchers should always be hunger of knowledge and in such contexts; the newcomer can be a good food for thought and practice. Hence, mixed designs have been a current practice among the novice and the expert researchers equally. This is evident from the proliferated practices in the research domain like universities, and research centres.

Further, in Leavy's (2017) views, "Mixed methods research (MMR) involves collecting and integrating quantitative and qualitative data in a single project and therefore may result in a more comprehensive understanding of the phenomenon under investigation" (p. 164). These reasons call for the intensive use of the MMRD.

\section{Historical Developments}

A glimpse of the MMRD can provide a huge impetus to the researchers for framing a proper research 
design. Thus, its historical overview is needed for the reachers.

The roots of the mixed designs are traced back to the beginning of the $20^{\text {th }}$ century, although mixing different methods "has an even longer history in disciplines such as ethology and animal behavior, palaeontology and geology" (Maxwell \& Loomis, 2003, as cited in Dörnyei, 2007, p. 43). The multiple methods of data were used since the 1930s (Sieber, 1973, as cited in Creswell, 2012). However, it was only 1959 when Campbell and Fiske practiced "multitraitmultimethod" research design in which they emphasized collecting more than one type of quantitative data (Creswell, 2010, p. 536 \&Dörnyei, 2007, p. 43). Thus, the early phase of MMRD dealt with mixing multiple quantitative data in a single study.

Using the single source of data appeared to be seen with skeptic eyes since the first half of the twentieth century. This context seems the cause for germination of the new way of inquiry. When positivism was a back-up philosophy for quantitative enquiry, ineterpretivism or constructivism was for qualitative. Qualitative research, in the beginning days, was brutally criticized by the positivists for lacking validity and reliability of the research process as a whole. To address this issue, the interpretivists preferred using multiple sources of data. For example, Denzin (1978) advocated methodological triangulation in which multiple qualitative methods would be used to maintain external and internal validity (as cited in Dörnyei, 2007). Triangulation, a term borrowed from naval military science, was used in research to mix up multiple data sources to investigate a single phenomenon. The multiple sources can be interviews, observations, documents, and the like. Similarly, Jick (1979) used triangulation by mixing up "surveys, semi-structured interviews, observations, and archival materials to provide "rich and comprehensive picture" (as cited in Creswell, 2012, p. 536) in a single study. There was a good rationale for blending this way to overcome the weaknesses of single method-boundedness and to maintain trustworthiness of the research data and process. In this way, MMRD has a legitimate shape methodologically for combining the strengths of the two and for overcoming weaknesses of one by the other.

Like methodological development of MMRD as a breakthrough in the 1970s, there was a philosophical breakthrough in the 1990s. It is a well-established fact in the domain of research that quantitative method was developed on the positivists'philosophy which assumed for a single objective reality that can be tested. The same well-established fact is that qualitative method drew heavily on interpretivists' or constructivists' philosophy which assumes for multiple subjective realities that depend on an individuals' perception on a phenomenon. Even criticalism or a critical assumption placed skepticism on the existing practices which enforced to introduce pragmatism as a background philosophy for MMRD (Creswell, 2012, \& 2014). In this way, the mixed methods have historical grounds of methodology and theory.

Before the 1990s, there was paradigm war between the positivists and the interpretivists as separate schools of thought. There was an issue of compatibility of the worldviews or paradigms and methods. The advocates of incompatibility argued that different worldviews and methods are not compatible as they were (Tashakkori \& Teddlie, 1998, as cited in Creswell, 2012). To put it differently, quantitative method is based on one worldview (e.g. single objective reality) whereas qualitative method on the other (multiple subjective realities perceived by one's own lens). This logic concludes that these two phenomena (i.e. qualitative and quantitative) are incompatible like sand and water and thus cannot be integrated or 
embedded in a single study. This notion, however, was understood as a fallacy later on as objective reality (e.g. observations of students' behaviour in a classroom) may have components of subjective realities (e.g. variability in the students' behaviours in a classroom culture) (Creswell, 2012). Thus, absolute dependency of an either method on a single paradigm proves wrong. This context opened up avenues for flourishing MMRD.

Further enhancement of the MMRD was observed when pragmatism was taken as its philosophical premise. For example, for Tashakkori and Teddlie (1998), pragmatism explores a particular research problem with the lens of multiple methods (as cited in Creswell, 2012). Likewise,Dörnyei (2007) has remarked Magnan's (2006) report which shows that “over the 1995-2005 period, 6.8 percent of the research papers appearing in the Modern Language Journal used mixed methods" (p. 44). This fact confirms that towards the end of the $20^{\text {th }}$ century, the MMRDemerged as a popular method of investigation based on pragmatism. Further, Mertens (2009) has asserted, “Other philosophies have emerged as a foundation for mixed methods research such as the transformative research perspective advancing the need for addressing issues of social justice for underrepresented groups" (as cited in Creswell, 2012, p. 537). In this way, the MMRD has come up with current interests and foundations philosophically and methodologically.

The forgoing paragraphs justify the demands of MMRD from methodological and philosophical perspectives. Beyond these dimensions, the paradigm war has been quietened by the development of its procedures for implementing MMRD (Creswell, 2012). Now, MMRD has its own notation system, fixed models and typologies, certain processes, and strengths to overcome single method-boundedness. For example, triangulation of different types, qualitative data support quantitative and vice versa concurrently or sequentially. Further, for large-scale projects "the data collection could extend from two to three phases (e.g.see Miles \&Huberman, 1994) or be collected from multiple levels in an organization such as the district, school, teacher and student (e.g. see Tashakkori \&Taddlie, 1998; Teddlie \&Tashakkori, 2009)" (as cited in Creswell, 2012, pp. 537-538). In this way, MMRD has been one of the research methods currently procedurally.

These methodological, philosophical and procedural perspectives have established MMRD as a legitimate research design. Therefore, different books, book chapters and journals offer reasonable space for MMRD research works are researchers. As nothing is complete in itself in general, MMRD is being amended. In this direction, Creswell (2012) has remarked, "Refinements continue in the process of data analysis inmixed methods research (Caracelli \& Greene, 1993), the use of computer programs for merging quantitative statistical programs with text analysis programs (Brazeley, 2000, 2010), and the identification and discussion of numerous mixed methods studies reported in the scholarly literature (e.g. Creswell \& Plano Clark, 20011; Geene et al., 1989)" (p. 538). This shows that MMRD one day has its potentiality to be the most effective research design as it has already played a crucial role to quieten the paradigm debate and also because it regards the research dynamics which calls for flexibility and open-endedness. In this conjecture, Creswell's (2012) remarks are worth quoting, "In the last 5 to 7 years, mixed methods has entered a new historical period in its evolution" (p. 539). It means that the emergence of MMRD has called upon some constructive criticisms from the veteran researchers in terms of its definition, scope, nature, 
process, philosophy, design, and the like.

These challenges are beneficial to settle with improvised MMRD in the research domain. These are the fruits of openness of the design and thus they facilitate to fill in the gap for further improvements like the use of technology to quantify qualitative data and to qualitize quantitative data.

\section{Salient Features of Each Typology}

As discussed before, the MMRD mixes up qualitative and quantitative in a way or the other. The two methods can be merged based on numerous organizing principles. However, Dörnyei (2007) has conceded two widely used principles of sequence and dominance. He has also provided these nine combinations based on only two components in a study:
(a) QUAL + QUAN
(b) QUAL + quan
(c) QUAN + qual
(d) QUAL $\rightarrow$ QUAN
(e) QUAN $\rightarrow$ QUAL
(f) QUAL $\rightarrow$ quan
(g) qual $\rightarrow$ QUAN
(h) QUAN $\rightarrow$ qual

(i) quan $\rightarrow$ QUAL

(Dörnyei, 2007, p. 169)

This classification exhibits that Dörnyei (2007) has used notations like the sign a plus (+) indicates a concurrent whereas an arrow $(\rightarrow$ ) represents a sequential collection of data; capital letters denote priority; and QUAL/qual stands for qualitative research whereas QUAN/quan quantitative research (Johnson \& Christensen, 2004, as cited in Dörnyei, 2007). In this way, the first three are concurrent whereas remaining six are sequential designs. Likewise, three types have dominance on the both qualitative and quantitative (a, d, \& e); three have dominance on qualitative (b, f, \& i); and other three have dominance on quantitative (c, g, \& h). Further, permutations and combinations make unlimited taxonomies and therefore MMRD is open for adding new designs following any suitable organizing principles.

However, Creswell (2012) has classified the MMRD based on four organizing principles such as priority, sequence of collecting data, way of data analysis, and the step in which the data are merged. Accordingly, he has classified the MMRD into two basis groups like the basic and the complex designs. The basic designs are convergent parallel, explanatory sequential, exploratory sequential, and embedded. The first one is like Dörnyei's (2007) 'QUAL + QUAN' or QUAN + QUAL' design in which emphasis lies on both the designs in collecting and analyzing the data simultaneously. That is why, it is also called concurrent parallel design. The second is like Dörnyei's (2007) 'QUAN $\rightarrow$ qual' design in which emphasis lies on quantitative data collection and analysis that follows qualitative data collection and analysis sequentially. The third is like Dörnyei's (2007) 'QUAL + quan' design in which emphasis lies on qualitative data collection and analysis that follows quantitative design in a sequence. The fourth one is a distinct one in which either quantitative or qualitative data collection and analysis supports either of the two simultaneously or sequentially. Creswell (2012) has also added two more complex designs based on the basic four. They are transformative and multiphase designs. The transformative design uses any of the four basic designs but frames the design within a transformative lens like feminist, racial, ethnic, disability, gay or lesbian perspectives. Finally, the multiphase design is used in large-scale project works. 
It also uses any of the four basic designs but is conducted in multiple phases/steps/projects. Nevertheless, the two complex models need to integrate or mix the results together to draw inferences, albeit they may diverge to each other. Creswell (2015a, 2015b) has also recommended convergent, exploratory sequential, and explanatory sequential as basic designs; and experimental/intervention, social justice/participatory, and multiphase programme evaluation as advanced designs. Of them, intervention is like embedded and social justice is like transformative design.

Similar typology has been suggested by Johnson, de Waal, Stefurak, and Hildebrand (2017), who have labeled MMRD as qualitatively driven, quantitatively driven and equal status. This classification is based on the emphasis given on the type of method. Accordingly, the first type emphasizes on qualitative component; the second on quantitative; and the third on both the types of approaches. This typology represents Creswell's $(2012,2014)$ three designs like convergent parallel (equal status), explanatory sequential (quantitatively driven), and exploratory sequential (qualitatively driven). However, this model does not incorporate other models like embedded, transformative, and multi-phase. Three-fold typology has also been recommended by Leavy (2017), who has used different terms such as convergent or concurrent, sequential, and nested. This taxonomy also represents Creswell's $(2012,2014)$ three types like convergent, sequential, and embedded. Nevertheless, Leavy (2017) has further categorized nested design into two types such as nesting qualitative data in quantitative design, and quantitative data in qualitative; and has also illustrated each type with examples.

The delineations expounded above prove that since Creswell's $(2012,2014)$ taxonomy is more exhaustive, applicable, and implementational; this is followed by many researchers and theorists. The taxonomy, which can be analysed in terms of purpose, rationale, process, researcher's role, strengths, and challenges, are discussed in the succeeding paragraphs.

Convergent parallel design (CPD). The name itself shows that the researcher in CPD collects and analyses the both forms of data concurrently (Creswell, 2012, 2014). Thus, the purpose of this design is to collect and analyze both the forms of data, to compare and contrast the results for the purpose of interpretation. The rationale of this design is that the strengths of both quantitative methods are integrated so that the new, i.e. CPD can be stronger enough to maintain validity and reliability. In this design, two or more researchers collect and analyze data simultaneously. These simultaneously collected and analyzed data are merged to answer the research questions. This comparison of the two datasets converges together for interpreting the results whether they yield similar or different findings.

The strength of this design is that quantitative data provides generalizability whereas qualitative data natural setting. For example, a researcher can conduct questionnaire survey whereas another researcher qualitative interview concurrently. The two datasets are compared to explore similarity/dissimilarity for the sake of interpretation. One major challenge in using this design is that the researchers have to mix up the results even if they may diverge. However, it is noteworthy that data collection and analysis are done separately for merging the data to draw the results (Creswell, 2012, 2014). Then, in the discussion section, the results are shown whether they are divergent or convergent. In case of divergent results, the researchers are suggested to revisit the datasets and/or to collect additional information for the investigation 
of convergence of the findings. In a nutshell, variability in sample sizes (more in quantitative or a few in qualitative), researchers and data sources should show convergence of findings, which sometimes is challenging because divergent results can be observed. Thus, the researchers, willing to conduct to this design should be aware of the pitfalls and hurdles of CPD to implement.

Explanatory sequential design (ESD1). Unlike CPD, in explanatory sequential design (ESD1) the researcher follows two-phase project in which strong quantitative follows the weak qualitative method. In ESD1, the researcher first collects and analyses quantitative data by means of questionnaire survey, structured interview, observation which a checklist, tests, and the like. Based on the qualitative results, $\mathrm{s} / \mathrm{he}$ plans for qualitative phase in which the data are collected by means or unstructured interview, unstructured observation, documents, records,verbal reports, texts/discourses, vignettes, and the like. Thus, ESD1 is not a concurrent but a sequential design.

The purpose of ESD1 is to collect and analyze quantitative (i.e. numerical) data and to corroborate the numerical scores by means of in-depth analyses (qualitative). The rationale of using ESD1 is that quantitative results provide a general superficial picture of a phenomenon whereas qualitative results offer in-depth understanding of the phenomenon. Therefore, the researcher first collects and analyses quantitative data, draws results, and enriches final findings by means of qualitative resultsdrawing on the previous results. It means qualitative interviews/observations facilitate explaining the survey responses. In other words, purposive sampling applied in qualitative phase is preceded by random sampling in quantitative phase. Thus, Creswell (2012) has claimed, "This design is useful for student research and perhaps easier to accomplish (than the convergent design) because one database builds on the other and the data collection can be spaced out over time" (p.273).

Like in CPD, interpretation is done in discussion section. For it, the researcher should first present quantitative results followed by qualitativeones. Only then, s/he shows how qualitative results support the quantitative ones. Thus, in whole research process, priority is given to quantitative phase; qualitative results refine, extend or explain the general picture drawn in the first phase; and interpretation of the results. One of the strengths of ESD1 is that the researchers need not integrate the two datasets. However, like other MMRDs, ESD1 in labor intensive, time-consuming, and calls for expertise on both qualitative and quantitative methods on the part of the researcher. Further, it is also challenging to follow the particular aspect of quantitative results in the second phase.

Exploratory sequential design (ESD2).Like ESD1, ESD2 is a sequential design in which the researcher follows strong quantitative method by quantitative one. This two-phase modelaims at collecting and analyzing data in a sequence, i.e. the researcher explores a phenomenon by a small-sized population but in-depth analysis of the themes. Based on the theme-analysis, large size population is tested by using quantitative means. Thus, ESD2 is a reversal of ESD1 in research process. The rationale of ESD2 is that qualitative themes support in designing quantitative tools. Therefore, emphasis lies to qualitative method; qualitative data collection and analysis follows quantitative ones for the corroboration of initial findings in qualitative phase. Like in CPD and ESD1, the researchers in this design interpret the results in the discussion section. The strength of this design is that themes can be tested for their generalizability. The 
challenges of ESD2 are like ones of ESD1.

Embedded design (ED). Embedded design (ED) has been categorized as a basic method in Creswell (2012) but as an advanced one in Creswell (2014). In ED, the researcher aims to collect and analyze both the forms of data simultaneously or sequentially but one form supports the other. The rationale of ED is to augment first form of the data by the other. In its process, the researcher collects and analyses quantitative and qualitative data in a single study separately to answer different research questions. Then, interpretation of results is presented in discussion section like in other MMRDs. ED differs from the other MMRDs that one form of data is embedded into the other. For example, within an experiment, the researcher can nest qualitative interview concurrently or sequentially. The strengths and weaknesses of ED are like of other MMRDs but further challenge involved in ED is that the researcher should embed the two forms of data in a single study.

Transformative design (TD). TD is a complex MMRD as TD follows any of the four designs, delineated above, but within a transformative framework, which may incorporate social justice theory, feminist/racist/lesbian/gay/ethnic/disability perspectives (Creswell, 2012, 2014). Thus, the purpose of TD is to encase CPD, ESD1, ESD2, or ED within a transformative lens. The rationale of TD is to dig out a phenomenon basing it within a perspective selected. The process involves merging both the forms of data and interpreting the results encasing them within a particular framework. For example, the researcher can explore the school dropouts within an ethnic lens. Firstly, s/he can survey using a questionnaire. Then, s/ he can narrow down the population and select particular ethnic groups and their responses in focus group interviews or participant observations to explore the reasons. Finally, s/he interprets the results seeing only through the ethnic glasses. Creswell (2012) has observed the strength of this design in terms of ideology and value; and the challenges in terms of integration of the lens into MMRD.

Multiphase design (MD).Like TD, this (MD) is also a complex or advanced design (Creswell, 2015). It is mainly conducted for large-scale projects. Thus, the purpose of this design is to address the incremental research issues and the rationale is that MD is useful to conduct multi-phase research projects. It is a popular design for large-scale projects, but challenges occur for forming a team of researchers, sequencing phases of research projects and establishing linkages among them. The process is to conduct multiple phases of any of the four basic designs.

Out of these six MMRDs, the researchers need to choose an appropriate one based on different factors like outcomes expected, process of data integration, time, emphasis on each database, suitability of the design for a field, single/multiple researchers and the like (Creswell, 2014). Therefore, the researcher considers multiple factors before selecting the type of mixed methods design.

\section{Assessment}

Since MMRD has been a popular design in research, pros and cons have been put forward. So far, it has been assessed valuable and useful for overcoming the shortcomings of monomethod designs (i.e. only quantitative or only qualitative). Dörnyei (2007) has mentioned the strengths of the monomethod design in these points: (a) Increasing the strengths while eliminating the weaknesses; (b) Multi-level analysis 
of complex issues; (c) Improved validity; and (d) Reaching multiple audiences (pp. 45-46). As indicated before, MMRD has emerged to erase the boundaries between the two poles of quantitative and qualitative methods. The supporters of either of the methods would claim that their side is superior to the other. To end the paradigm war, this design was introduced. Therefore, attraction to this newer paradigm is because of the mixing up of the strengths of each method and blurring its weaknesses. For example, quantitative researchers charge qualitative research to be subjective, invalid, unreliable, context-specific, and too small in sample size (Denzin \& Lincoln, 2018). However, if qualitative research follows or precedes quantitative sampling, the charge can be neutralized. Likewise, qualitative researchers blame quantitative research to be too "simplistic, decontextualized and reductionist in terms of its generalizations, failing to capture the meanings" (Brannan 2005, as cited in Dörnyei, 2007). If quantitative research precedes or follows the qualitative process, the charge can be neutralized. In this way, MMRD increases strengths by eliminating weaknesses of monomethod designs.

Secondly, complex issues can be better addressed by combining numerical data that can be generalized and verbal data that offer in-depth analysis of meaning making process between the lines of the expressed verbatim. In this regard, Dörnyei's(2007) remark is worth mentioning, "Words can be used to add meaning to numbers and numbers can be used to add precision to words" (p. 45). Thus, multi-level analysis is appropriate for fuller exploration of phenomena. This context supports the use of MMRD.

Thirdly, validity in research is a crucial issue and thus it should be maintained well in research work. In MMRD, triangulation of different types (like data, method, theory, researcher, and so on) is well catered for maintaining validity. Corroboration of both the forms of data and analysis increases external validity (generalizability in quantitative method and transferability in qualitative research). Further, multiple data sources in the both forms of data increase not only internal and external validity but also reliability. In MMRD, these qualities increase trustworthiness and rigor of the researchers.

Fourthly, the final outcomes of the mixed methods are acceptable both for qualitative and quantitative researchers. However, the MMRD researcher should be aware of "paradigmatic crack" which may cause the results to be of nowhere (Dörnyei, 2007, p. 46).

As a coin has two sides, MMRD is not beyond criticism. However, it is too early to attack MMRD severely. If the researcher is not expert in both the methods (i.e. QUAN and QUAL), s/he will run after two hones and will catch none. Further, such researchers will fall prey of a lamb owned by two masters is eaten by the wolf. Thus, it is advisable that the researchers who do not have mastery over the two edges (e.g. QUAN and QUAL) should not use MMRD. The next issue can be the organizing principles for mixing up the methods. MMRD is open-ended and flexible enough to emerge new combinations. No typologies are fixed. Therefore, if not handled carefully, and skillfully, the researchers cannot reach the destinations they fix to reach. Despite these limitations, the current trend of MMRD use shows that it can be the research design of the future,too.

\section{Conclusion and Implications}

The emergence of mixed methods research design (MMRD) is based on the assumption that it can weaken the loopholes and strengthen the brighter aspects of the monomethod designs like quantitative or 
quantitative alone. The paradigm war of the mid-twenties between the poles of the two strands ended with the use of the MMRD that creates its own space as an advanced research design. Multifarious reasons (like its encapsulation of the strengths of the two strands, proliferation of university research works, and so on) have settled this newcomer as an effective research design of the day. This design has also been approved philosophically (i.e. pragmatism), methodologically, and procedurally. This is evidenced in the study of its historical developments and its current practices.

Two main sub-designs like basic and advanced are being adopted. The former includes concurrent, sequential, and embedded; whereas the latter transformative, and multiphase designs. In concurrent design two datasets are collected and analyzed simultaneously; in sequential design the datasets are collected and analyzed in a sequence; and in nested design one set of data is embedded within the other. Further, sequential design can be explanatory or exploratory based on the priority on quantitative or qualitative component respectively. The advanced designs call for the use of any of them; nevertheless they can be encased within a frame (transformative design) or conducted in multiple steps (multiphase design). Of these two, the former design subsumes social justice/participatory and the latter multistage programme evaluation. Furthermore, the MMRD is an emergent design and thus it is open for the newer designs, too.

Although it is too early to assess its fruits, the MMRD has been backed-up by the proliferation of university studies, books, book chapters, journals, and the like. These trends imply that MMRD should take a considerable space in the courses of the universities; proliferate by means of studies and publications; and be the genre for freelance researchers.

\section{References}

Al-Jardani, K. S. S. (2012). English language curriculum evaluation in Oman. International Journal of English Linguistics, 2 (5), 40-44. doi: 10.5539/ijel.v2n5p40.

Anderson, V. R. (2016). Introduction to mixed methods approaches. In L. A. Jason \& D. S. Glenwick (Eds.), Handbook of methodological approaches to community-based research: Qualitative, quantitative, and mixed methods (pp. 233-241). New York: Oxford University Press.

Brown, J. D., \& Rodgers, T. S. (2014). Doing second language research. New York: Oxford University Press. First published 2002.

Creswell, J. W. (2012). Educational research: Planning, conducting, and evaluating quantitative and qualitative research (4thed.). Boston: Pearson.

Creswell, J. W. (2014).Research design: Qualitative, quantitative, and mixed methods approaches (4th $\mathrm{ed}$.). Thousand Oaks, CA: Sage.

Creswell, J. W. (2015a).A concise introduction to mixed methods research. Los Angeles: Sage.

Creswell, J. W. (2015b). Revisiting mixed methods and advancing scientific practices. In S. Hesse-Biber, \& R. B. Johnson (Eds.), The Oxford handbook of multimethod and mixed methods research inquiry (pp. 57-71). New York: Oxford University Press.

Denzin, N. K., \& Lincoln, Y. S. (Eds.). (2018). The Sage handbook of qualitative research (5 ${ }^{\text {th }}$ ed.). Los Angeles: Sage. 
Dörnyei, Z. (2011). Research methods in applied linguistics. New York: Oxford University Press. First published 2007.

Hay, M. C. (2016). Preface: Applying methods that matters. In M. C. Hay (Eds.), Methods that matter: Integrating mixed methods for more effective social science research (pp. xi-xvi). Chicago \& London: The University of Chicago Press.

Hesse-Biber, S., \& Johnson, R. B. (Eds.). (2015). The Oxford handbook of multimethod and mixed methods research inquiry. New York: Oxford University Press.

Johnson, R. B., de Waal, C., Stefurak, T., \& Hildebrand, D. L. (2017). Understanding the philosophical positions of classical and neopragmatists for mixed methods research. doi: 10.1007/s11577-0170452-3.

Krippendorff, K. (2013). Content analysis: An introduction to its methodology. USA: Sage.

Leavy, P. (2017). Research design: Quantitative, qualitative, mixed methods, arts-based, and communitybased participatory research approaches. New York \& London: The Guilford Press.

Dr. Nabaraj Neupane is a Reader (Associate Professor) in English Education at Tribhuvan University, Nepal. He is a teacher trainer and the President of NELTA Gandaki Province, Pokhara. He has been honoured with Nepal Vidhyabhusan Ka by Nepal Government. To his credit, more than four dozens of articles have been published in different journals from home and abroad. He has also published books, edited journals, translated literary texts, and presented papers in national and international conferences. His professional interests include Research Methodology, Translation Studies, SLA, Pragmatics, Discourse Analysis, and Use of ICT in ELT. 